\title{
Four decades of experience with mitral valve repair: Analysis of differential indications, technical evolution, and long-term outcome
}

\author{
Daniel J. DiBardino, MD, Andrew W. ElBardissi, MD, R. Scott McClure, MD, \\ Ozwaldo A. Razo-Vasquez, MD, Nicole E. Kelly, RN, and Lawrence H. Cohn, MD
}

\begin{abstract}
Objective: To determine the long-term outcomes of mitral valvuloplasty for myxomatous valve disease, rheumatic valve disease, and functional mitral regurgitation.
\end{abstract}

\begin{abstract}
Methods: A total of 1503 patients underwent mitral valvuloplasty by a single surgeon between February 1972 and April 2008 and were retrospectively reviewed for short- and long-term results. Overall mean age was 60.3 \pm 13.7 years, and $57 \%$ were male. The cause was rheumatic in 193 patients, myxomatous in 1042 patients, and ischemic and nonischemic functional mitral regurgitation in 236 patients. Ring annuloplasty was performed in 1306 patients $(87 \%)$. Commissurotomy was the primary repair for rheumatic valves, posterior leaflet resection and reconstruction was the most common repair for myxomatous valves (527/1042 [51\%]), and ring reduction annuloplasty was the primary operation for functional mitral regurgitation.
\end{abstract}

Results: The 30-day mortality was 19 of 1503 patients (1.3\%) and significantly higher in the functional mitral regurgitation group (11/236 patients, $4.7 \%$ vs $0.5 \%$ in the rheumatic group and $0.6 \%$ in the myxomatous group, $P<.01)$. The 10-, 20-, and 30-year survivals were similar for the rheumatic and myxomatous groups $(77 \%, 56 \%$, and $39 \%$ vs $79 \%, 62 \%$, and $52 \%$, respectively) but significantly less for the functional mitral regurgitation group $(44 \%, 4 \%$, and $0 \%$, respectively, log-rank $P<.0001)$. The 10 - and 20 -year freedom from reoperation rates were significantly better for the myxomatous group than for the rheumatic group $(90 \%$ and $82 \%$ vs $66 \%$ and $34 \%$, $\log$-rank $P<.0001$ ), with a 30-year freedom from reoperation of only $10 \%$ for rheumatic repair. In the myxomatous group, freedom from reoperation was lower in patients with anterior leaflet pathology $(P=.0008)$.

Conclusion: Follow-up data to 36 years demonstrate that cause strongly determines survival and durability of mitral valvuloplasty; patients with rheumatic valve disease who survive more than 20 years require reoperation, whereas functional mitral regurgitation carries the highest short- and long-term mortality rates and lowest freedom from reoperation. Mitral valvuloplasty for myxomatous valves demonstrates the longest durability, with many patients free from reoperation at 30 years. (J Thorac Cardiovasc Surg 2010;139:76-84)

Mitral valvuloplasty (MVP) is one of the oldest operations in cardiac surgery. The first successful MVP operation was performed at Brigham and Women's Hospital by Elliot Cutler in $1923 .{ }^{1}$ Harken and colleagues ${ }^{2}$ followed Cutler's lead, performing a series of closed MVPs beginning in 1948. Lillehei and colleagues ${ }^{3,4}$ made early contributions to the understanding of the importance of the subvalvar apparatus to ventricular performance in the late 1950s, leading to progressive efforts in valve repair. Modern MVP on cardiopulmonary bypass (CPB) began at Brigham and Women's Hospital in 1972, and given the diverse repairable mitral valve (MV) pathology over the years, we sought to evaluate the long-term performance of mitral repair strategies among different MV disease causes to compare and contrast long-term survival and repair durability.

From Brigham and Women's Hospital, Harvard Medical School, Boston, Mass. Received for publication May 11, 2009; revisions received July 21, 2009; accepted for publication Aug 7, 2009; available ahead of print Nov 20, 2009.

Address for reprints: Lawrence H. Cohn, MD, Virginia Hubbard Professor of Surgery,

Cardiac Surgery, Harvard Medical School, Brigham and Women's Hospital, 75

Francis Street, Boston, MA 02215 (E-mail: lcohn@partners.org).

$0022-5223 / \$ 36.00$

Copyright (c) 2010 by The American Association for Thoracic Surgery doi:10.1016/j.jtcvs.2009.08.058

\section{MATERIALS AND METHODS}

By using an institutional review board-approved protocol, all MVPs performed by a single surgeon (L.H.C.) through April 2008 were identified and collected on a Microsoft Excel spreadsheet (Microsoft Corp, Redmond, Wash). Inclusion criteria were first-time MVP operations performed on CPB. Complex congenital lesions affecting the MV (partial and complete atrioventricular canal, idiopathic hypertrophic subaortic stenosis) were excluded. A small group of patients $(<10)$ who underwent a feasibility study with "robotic-assisted" MVP were also excluded because we wanted to evaluate the long-term outcomes of standard approaches. Patients were not excluded if concomitant other cardiac procedures were performed during MVP.

All available operative and postoperative follow-up data were reviewed, and long-term follow-up was obtained by searching local electronic health records, office charts, cardiology office follow-up visits, mail surveys, and telephone follow-ups. Vitality statistics for all patients were doubly verified using the website of the United Stated Social Security Death Index. Death was categorized as either 30-day or late mortality, whereas MV reoperation was any MV procedure performed after exiting the operating room on conclusion of the index repair. All echocardiographic data regarding valvar regurgitation were verified on the official study report and coded on a scale of 0 to $4(0=$ none, $1=$ trivial, $2=$ mild, $3=$ moderate, and $4=$ severe) with decimals used to code in-between qualitative descriptions. Statistical analysis was performed with SAS (SAS Institute, Inc, Carey, NC). All categoric data are expressed as mean (median sometimes also given as indicated) \pm standard deviation with $25 \%$ 


$$
\begin{aligned}
& \text { Abbreviations and Acronyms } \\
& \begin{aligned}
\text { AVR } & =\text { aortic valve replacement } \\
\text { CABG } & =\text { coronary artery bypass graft } \\
\text { CPB } & =\text { cardiopulmonary bypass } \\
\text { ETE } & =\text { edge-to-edge } \\
\text { FMR } & =\text { functional mitral regurgitation } \\
\text { IQR } & =\text { interquartile range } \\
\text { MV } & =\text { mitral valve } \\
\text { MVP } & =\text { mitral valvuloplasty } \\
\text { SAM } & =\text { systolic anterior motion }
\end{aligned}
\end{aligned}
$$

and $75 \%$ interquartile ranges provided. Any inferential statistical analysis is described according to methodology. All long-term reoperation data are reported using actuarial Kaplan-Meier analysis for comparison by log-rank analysis. All long-term survival data are presented as a Cox proportional hazard curve.

\section{RESULTS}

There were 1503 consecutive MVPs performed by a single surgeon from February 23, 1972, to April 30, 2008. Overall, there were 858 men $(57 \%)$ and 645 women $(43 \%)$ with a mean age of $60.3 \pm 13.7$ years (interquartile range [IQR], 51-71). Cause of MV disease was myxomatous in 1042 patients, ischemic in 236 patients, and nonischemic functional mitral regurgitation (FMR) and rheumatic in 193 patients (Table 1). The first 34 patients in the series had rheumatic MV disease, and the first myxomatous valve was repaired on September 29, 1976. The first repair of ischemic FMR occurred on June 18, 1981, using a Carpentier (Edwards Lifesciences, Irvine, Calif) ring remodeling annuloplasty with a concomitant 4-vessel coronary artery bypass graft (CABG).

First-time MV repair was done as a reoperation in 57 patients $(3.8 \%)$, including 36 patients with previous CABG $(2.4 \%), 6$ patients $(0.4 \%)$ with previous CABG and aortic valve replacement (AVR), 6 patients $(0.5 \%)$ with previous $\mathrm{AVR}$, and 6 patients $(0.5 \%)$ with previous closed MV commissurotomy. Incision types included full sternotomy in 861 patients $(57 \%)$, right thoracotomy in 15 patients $(1 \%)$, right parasternal in 134 patients $(9 \%)$, and hemisternotomy in 493 patients (33\%); the differential use of incision types per decade is illustrated in Figure 1. Of the minimally invasive incisions, the right parasternal approach never required conversion but was ultimately aban- doned because of concerns for late lung herniation. The hemisternotomy approach was converted to full sternotomy 6 times $(6 / 493,1.2 \%)$ between 2001 and 2007 because of the inability to defibrillate in 2 cases, poor exposure in 3 cases, and an acute dissection of the ascending aorta in 1 case.

Ring annuloplasty was performed as part of MVP in 1306 patients $(87 \%)$ and was increasingly more common after the first decade, once annuloplasty rings became widely available; only 6 rings were implanted in 99 consecutive repairs from 1972 to 1984, after which 1300 rings were implanted in the next 1404 patients. Implants included 9 different ring designs over 36 years, the most common of which was the Cosgrove-Edwards ring (Edwards Lifesciences) (Table 2). Leaflet repair techniques were performed with principles originally reported by Carpentier ${ }^{5}$ and Duran and colleagues, ${ }^{6}$ but several simplified modifications based on these principles were increasingly used. ${ }^{7,8}$ Intraoperative transesophageal echocardiography has been used routinely for intraoperative assessment of MV repair since 1990. On the basis of unsatisfactory transesophageal echocardiogram findings, a second crossclamp application to adjust MVP was necessary in 24 patients $(1.6 \%)$, all resulting in satisfactory repair. Concomitant procedures were performed in 609 of 1503 patients: 248 CABG procedures $(17 \%)$ and 361 other procedures $(24 \%)$, with 88 patients undergoing CABG and other procedures.

The overall 30-day mortality was $1.3 \%$ (19/1503). Although a "decade" effect has been described for large groups of patients undergoing cardiovascular operation over several decades, we did not identify such a phenomenon; the operative mortality rate was $0 \%(0 / 55)$ in the $1970 \mathrm{~s}, 1.8 \%(3 / 166)$ in the $1980 \mathrm{~s}, 1.4 \%(7 / 488)$ in the $1990 \mathrm{~s}$, and $1.1 \%(9 / 794)$ in the $2000 \mathrm{~s}$ (chi-square, $P=.97)$. The overall mean hospital stay for the entire series was $7.6 \pm 7.6$ days (IQR, $5-8$ ), and there was no statistical significance in hospital stay per decade (analysis of variance, $P=.1704)$. Among patients with myxomatous disease, rheumatic disease, and FMR, definitive longterm survival data were available for analysis in 1432 of 1465 patients $(98 \%)$ up to 36 postoperative years (total 10,390 patient years), and definitive reoperation data were available for analysis in 1214 of 1465 patients $(83 \%)$ up to 30 postoperative years (total 6249 patient years). These data are presented below in time-related analysis with numbers at risk provided in all cases.

TABLE 1. Cause and basic demographics of the three major etiologic subtypes of 1503 patients undergoing mitral valve repair from 1972 to 2008

\begin{tabular}{llrlcccc}
\hline \multicolumn{1}{c}{ Cause } & $\mathbf{n}$ & Male (\%) & Age $(\mathbf{y})$ & MV area $\left(\mathbf{c m}^{2}\right)$ & MV gradient $(\mathbf{m m ~ H g )}$ & $\%$ Ejection fraction & $\%$ Severe MR \\
\hline Rheumatic & 193 & $28(15 \%)$ & $54 \pm 15$ & $1.2 \pm 0.4$ & $12.9 \pm 9.7$ & $58 \pm 10$ & $25 \%$ \\
Myxomatous & 1042 & $692(66 \%)$ & $59 \pm 13$ & - & - & $61 \pm 9$ & $84 \%$ \\
FMR & 236 & $123(52 \%)$ & $69 \pm 10$ & - & $43 \pm 13$ & $62 \%$ \\
\hline
\end{tabular}

$M V$, Mitral valve; $M R$, mitral regurgitation; $F M R$, functional mitral regurgitation. 


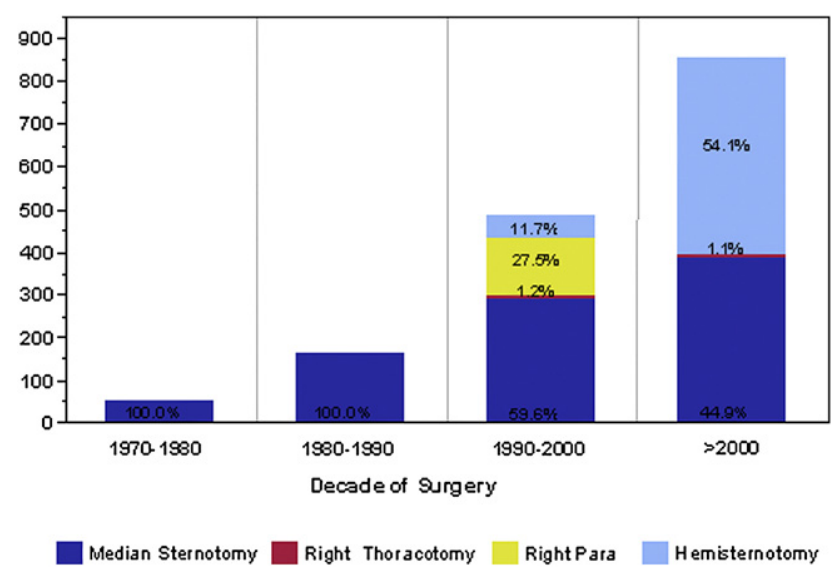

FIGURE 1. Relative incision use for 1503 patients undergoing MV repair between 1972 and 2008. There were 861 full sternotomies (57\%), 493 hemisternotomies (33\%), 134 right parasternal incisions (9\%), and 15 right thoracotomies $(1 \%)$

\section{Results of Repair for Rheumatic Valve Disease}

Rheumatic valve disease in 193 patients was repaired over 4 decades; analysis was possible in 187 patients (Table 1). These patients were significantly younger than those with myxomatous valve disease $(P<.0001)$ and FMR $(P<$ .0001 , paired $t$ test), and most were female $(85 \%)$ with preserved ejection fraction $(57.9 \% \pm 10.1 \%$; IQR, $52.9 \%$ $65 \%$; Table 1). Variable combinations of echocardiogram and catheterization data were used in preoperative decision making; the mean preoperative MV area was $1.2 \pm 0.4$ $\mathrm{cm}^{2}$ with a mean gradient of $12.9 \pm 9.7 \mathrm{~mm} \mathrm{Hg}$, with severe MR present in $25 \%$ of the preoperative studies (Table 1). Six patients with rheumatic valve disease had undergone closed MV commissurotomy by Harken and colleagues ${ }^{2}$ between 1955 and 1972, and 1 patient had undergone previous AVR.

CPB time was $67.1 \pm 29.5$ minutes (IQR, 42-90), and aortic crossclamp time was $50.1 \pm 27.4$ minutes (IQR, 23-69). Repair consisted mainly of unilateral and bilateral commissurotomy with variable extension into the subvalvar apparatus. Ring annuloplasty was not used in 126 of 193 patients $(67.4 \%)$; 61 rings were implanted, including a Carpentier ring in 14 patients, a Duran ring (Medtronic Inc, Minneapolis, Minn) in 5 patients, and a Cosgrove ring in 42 patients. The mean size for the 61 implanted rings was $30 \pm 2.9 \mathrm{~mm}$ (median, $30 \mathrm{~mm}$; IQR, 28-32). No patient required a second CPB or crossclamp time. Concomitant procedures were performed in 57 of 187 patients $(31 \%)$, including 12 CABGs and 52 other cardiac procedures (eg, other valve, arrhythmia procedures). The 30-day mortality for rheumatic repair was $0.5 \%$ (1/187 patients) with a hospital stay of $8.3 \pm 4.4$ days (IQR, 6-90). The 10-, 20-, and 30 -year survivals were $77 \%, 56 \%$, and $39 \%$, respectively (Figure 2), and freedoms from MV reoperation were $66 \%$, $34 \%$, and $10 \%$ at 10, 20, and 30 years, respectively (Figure 3 ).
TABLE 2. Ring annuloplasty implantation types used in 1503 patients undergoing mitral valve repair between 1972 and 2008

\begin{tabular}{|c|c|c|}
\hline MV ring type & n $(\%)$ & First implant \\
\hline None & $197(13 \%)$ & $2 / 23 / 1972$ \\
\hline $\begin{array}{c}\text { Carpentier-Edwards (Edwards } \\
\text { Lifesciences, Irvine, Calif) }\end{array}$ & $49(3 \%)$ & 9/29/1976 \\
\hline $\begin{array}{r}\text { Duran (Medtronic Inc, } \\
\text { Minneapolis, Minn) }\end{array}$ & $178(12 \%)$ & $12 / 23 / 1985$ \\
\hline $\begin{array}{l}\text { St Jude Bi-Flex (St Jude } \\
\text { Medical, St Paul, Minn) }\end{array}$ & $1(1 \%)$ & 9/19/1991 \\
\hline $\begin{array}{l}\text { Cosgrove-Edwards (Edwards } \\
\text { Lifesciences) }\end{array}$ & $1023(68 \%)$ & $5 / 17 / 1994$ \\
\hline $\begin{array}{l}\text { Pericardium (hand } \\
\text { constructed) }\end{array}$ & $2(1 \%)$ & $3 / 9 / 1998$ \\
\hline $\begin{array}{l}\text { Medtronic Future GC } \\
\text { (Medtronic Inc) }\end{array}$ & $8(1 \%)$ & $2 / 20 / 2003$ \\
\hline $\begin{array}{l}\text { Colvin-Galloway (Medtronic } \\
\text { Inc) }\end{array}$ & $1(1 \%)$ & $6 / 14 / 2004$ \\
\hline $\begin{array}{l}\text { Carpentier-Edwards Physio } \\
\text { (Edwards Lifesciences) }\end{array}$ & $25(2 \%)$ & $6 / 8 / 2005$ \\
\hline $\begin{array}{l}\text { GeoForm (Edwards } \\
\text { Lifesciences) }\end{array}$ & $7(1 \%)$ & $6 / 8 / 2006$ \\
\hline Unknown & $12(1 \%)$ & - \\
\hline
\end{tabular}

\section{Results of Repair for Myxomatous Valve Disease}

As seen in Table 1 , patients with myxomatous disease were older than patients with rheumatic disease $(P<$ $.0001)$ and younger than those with FMR $(P<.0001$, paired $t$ test), were more often male $(66 \%)$, had largely preserved ejection fraction (mean, $61.4 \% \pm 8.7 \%$; IQR, $58 \%-$ $65 \%$ ), and had moderate to severe MR with MR graded as severe in $84 \%$ (Table 3). Intraoperative inspection and description described leaflet involvement as posterior only in 683 patients $(66 \%)$ and involving the anterior leaflet in 338 patients (32\%); of the latter, 271 patients had bileaflet involvement and 67 patients had isolated anterior leaflet involvement. In 7 patients, MV repair was performed as a cardiac reoperation, including 4 previous CABGs, 2 previous AVRs, and 1 previous composite valve graft replacement of an ascending aortic aneurysm.

Mean CPB time was $112 \pm 31$ minutes (IQR, 90-128), and mean aortic crossclamp time was $78 \pm 20$ minutes (IQR, 65-90). Ring annuloplasty was used in the majority of myxomatous repairs $(987 / 1042,95 \%)$, including Cosgrove $(\mathrm{n}=820)$, Duran $(\mathrm{n}=142)$, and Carpentier $(\mathrm{n}=20)$ rings with a mean size of $33 \pm 3.7 \mathrm{~mm}$ (IQR, 30-36). In terms of leaflet techniques, we identified 97 different repair combinations with posterior leaflet resection and commissuroplasty making up the most common building blocks of repair (Table 4). Although many patients with isolated anterior leaflet pathology $(47 / 67,70 \%)$ underwent repairs involving the anterior leaflet, 20 patients did not (17 with only commissuroplasty and 3 with only ring implantation; Table 4). The most common procedure for 


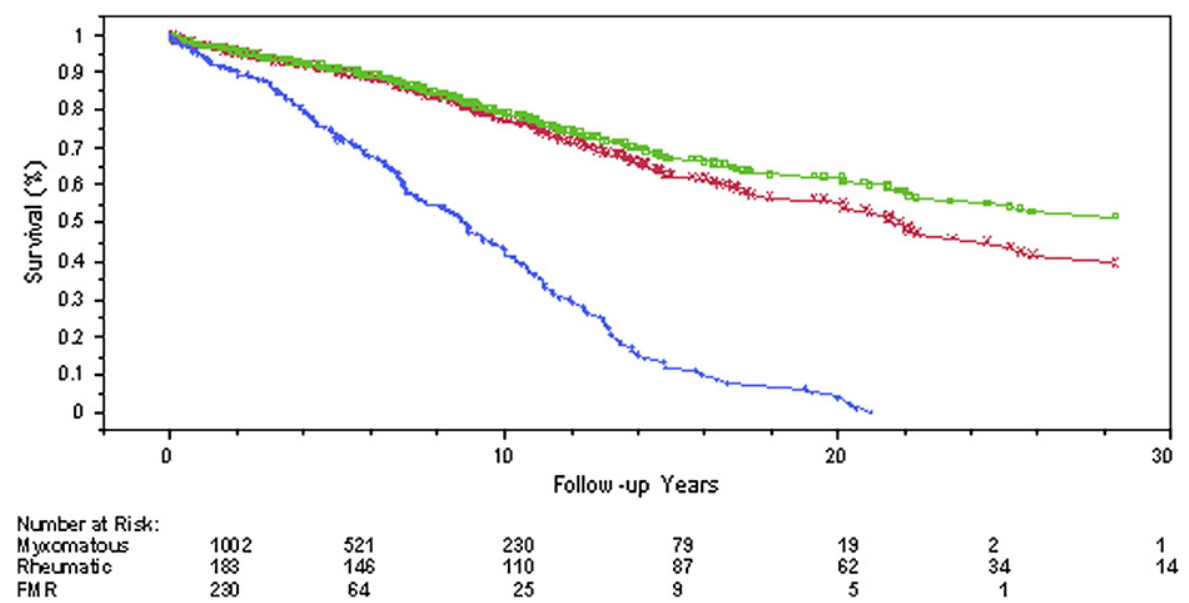

FIGURE 2. Cox proportional hazard model of long-term survival after MV repair for rheumatic (red), myxomatous ( green), and ischemic/nonischemic FMR (blue) disease to 30 years postoperatively. FMR, Functional mitral regurgitation.

patients with involvement of both leaflets was a posterior repair only $(129 / 271,48 \%)$, whereas posterior repair plus edge-to-edge (ETE) repair was used after 1999 (62/271, $23 \%$ ), as we previously reported as part of our strategy to avoid systolic anterior motion (SAM) (Table 4). Only 67 patients with bileaflet involvement $(25 \%)$ were thought to require a combined posterior and anterior leaflet repair, and the majority of these were earlier in the series. There were 123 concomitant CABGs $(12 \%)$ and 174 other cardiac procedures $(17 \%)$, with 22 patients undergoing both $\mathrm{CABG}$ and other procedures in addition to MVP.

Twenty-two patients with myxomatous disease (22/1042, $2.1 \%$ ) required a second $\mathrm{CPB}$ and crossclamp application for persistent MR, mitral stenosis, or SAM, leaving the patient with an acceptable MVP result in each case. All other patients left the operating room with no or trace MR and an acceptable gradient. Significant mitral stenosis was detected in 4 patients $(0.4 \%)$ and was treated in each instance by removal of a previously placed ETE stitch. Significant residual MR was found in 6 patients $(0.6 \%), 3$ of whom had leaflet tethering from a portion of the new repair: The anterior leaflet polytetrafluoroethylene (Gore-Tex; WL Gore \& Associates Inc, Newark, Del) neochords were too short in

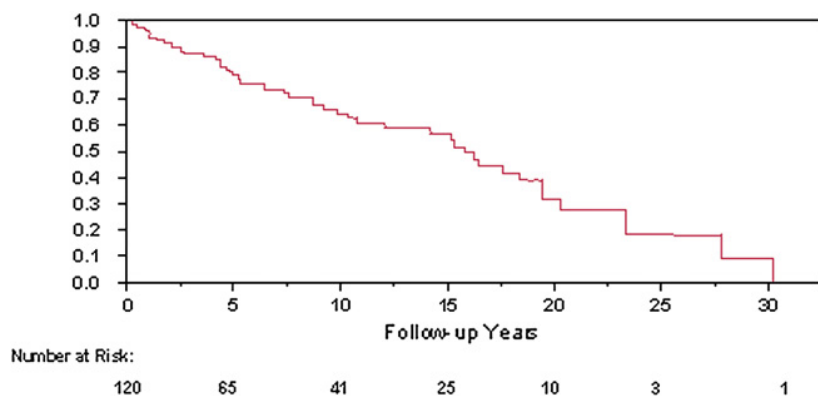

FIGURE 3. Kaplan-Meier long-term freedom from mitral reoperation after repair for rheumatic MV disease to 30 years postoperatively.
2 patients, and an anterolateral commissuroplasty tethered the commissure open in 1 patient. All 3 patients responded to removal of the offending suture. The addition of an ETE repair, an additional commissuroplasty stitch, and a repair of a dehisced P2 reconstruction treated the remaining 3 patients. Severe post-bypass SAM was detected and surgically treated in 12 patients $(1.2 \%)$, with no case occurring since January of 2006, corresponding to our publication for the indications of prophylactic ETE suture application in cases with high SAM potential. ${ }^{9}$

The 30-day mortality for myxomatous repair was $0.6 \%$ (6/1042 patients) and not significantly different from those with rheumatic disease $(P=.95)$. The 10-, 20-, and 30year survivals were $79 \%, 62 \%$, and $52 \%$, respectively (Figure 2), and the freedoms from reoperation at 10 and 20 years were $90 \%$ and $82 \%$, respectively, significantly better than for rheumatic valve disease (Figure 4, log-rank $P<$ .0001). Figure 5 demonstrates differential freedom from MV reoperation based on posterior leaflet involvement

TABLE 3. Precise repair combinations performed most frequently $(\geq 20)$ in 1042 patients undergoing repair of myxomatous mitral valve disease between 1972 and 2008

\begin{tabular}{lc}
\hline \multicolumn{1}{c}{ Repair technique } & n (\%) \\
\hline Posterior leaflet resection with reconstruction & $527(51 \%)$ \\
Commissuroplasty $\times 1$ & $52(5 \%)$ \\
Posterior leaflet resection with reconstruction, & $49(5 \%)$ \\
$\quad$ commissuroplasty $\times 1$ & \\
Posterior leaflet resection with reconstruction, & $40(4 \%)$ \\
$\quad$ Alfieri stitch & $37(4 \%)$ \\
Posterior leaflet imbrication (“fold-o-plasty") & $26(3 \%)$ \\
$\begin{array}{l}\text { Posterior leaflet resection with reconstruction, } \\
\quad \text { débridement of MAC }\end{array}$ & $21(2 \%)$ \\
Posterior leaflet resection with reconstruction, \\
$\quad$ commissuroplasty $\times 2$
\end{tabular}


TABLE 4. Repairs performed in 338 patients with myxomatous disease with anterior leaflet involvement between 1972 and 2008

\begin{tabular}{lc}
\hline \multicolumn{1}{c}{ Bileaflet pathology } & $\mathbf{n = 2 7 1}(\mathbf{8 0} \%)$ \\
\hline Posterior repair only (including commissuroplasty) & 129 \\
Posterior repair + Alfieri & 62 \\
Posterior repair + anterior resection & 25 \\
Posterior repair + polytetrafluoroethylene (Gore-Tex; & 25 \\
$\quad$ WL Gore \& Associates Inc, Newark, Del) artificial & \\
$\quad$ chords & 15 \\
Posterior repair + chordal shortening & 15 \\
Other & $\mathrm{n}=67(20 \%)$ \\
Anterior leaflet pathology & $17(25 \%)$ \\
Commissuroplasty only & $3(5 \%)$ \\
Ring only & $47(70 \%)$ \\
Anterior leaflet repairs & 18 \\
$\quad$ Artificial polytetrafluoroethylene (Gore-Tex) & \\
$\quad$ chords (6 with commissuroplasty, 2 with small & \\
$\quad$ anterior resection) & 13 \\
Alfieri stitch (1 with commissuroplasty, 1 with & \\
$\quad$ anterior perforation closure) & \\
Anterior leaflet resection with reconstruction only & 7 \\
Other & \\
\hline These repairs were combined with ring implantation in 322 of 338 patients $(95 \%)$.
\end{tabular}

only versus pathology involving the anterior leaflet; 10 - and 20 -year freedoms from reoperation were higher for posterior leaflet only ( $93 \%$ and $88 \%$ vs $84 \%$ and $74 \%$, respectively, $\log$-rank $P=.0008)$.

Durability of repair was further assessed by evaluation of the last known postoperative echocardiogram. Of 1042 patients, 62 had reoperation such that assessment of postrepair by echocardiography was possible in 980 . The last available echocardiogram was located for 604 of these patients, with studies extending to 21.3 years postoperatively (2419 patient years), whereas extremely wide variation in cardiology patterns of echocardiogram attainment resulted in a mean time from surgery to last echocardiogram of only $4 \pm 3.5$ years. Studies demonstrated severe MR in 5 patients $(0.8 \%)$, moderate to severe MR in 6 patients $(1 \%)$, and moderate MR in 49 patients $(8 \%)$. The incidence of significant mitral stenosis on postoperative echocardiogram

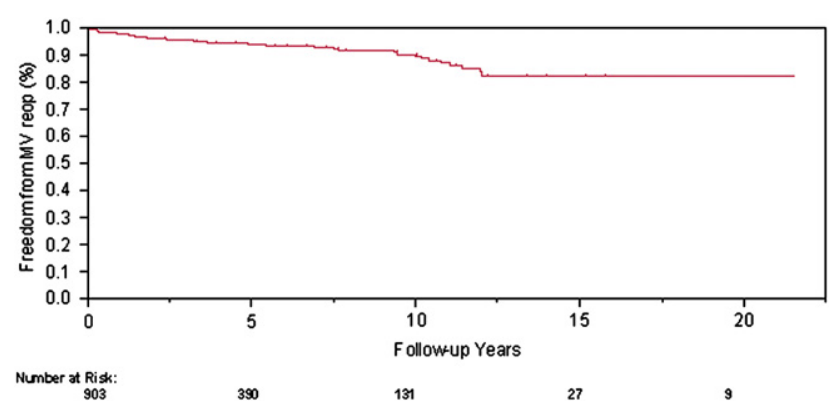

FIGURE 4. Kaplan-Meier actuarial freedom from MV reoperation after repair for myxomatous MV disease to 22 years postoperatively.

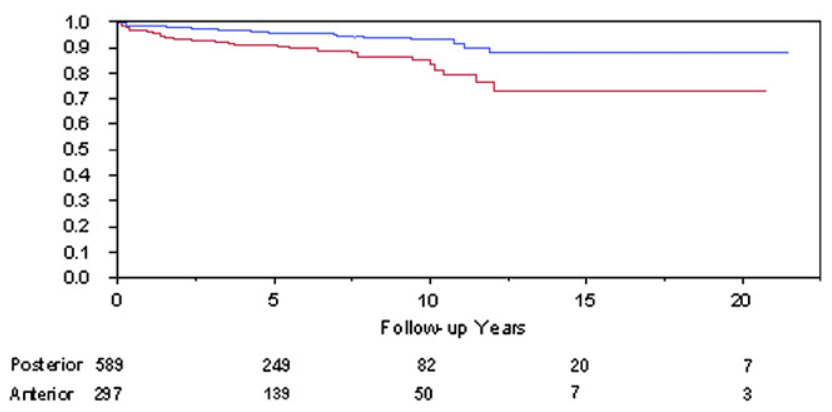

FIGURE 5. Differential Kaplan-Meier actuarial freedom from MV reoperation according to valves with posterior leaflet only pathology (black, $\mathrm{n}=683$ ) versus valves with anterior leaflet pathology ( rey, $\mathrm{n}=338$ ) to 22 years postoperatively.

was low $(9 / 604$ patients, $1.5 \%) ; 6$ cases were moderate $(1 \%), 2$ cases were moderate to severe $(0.3 \%)$, and 1 case was severe $(0.2 \%)$.

\section{Results of Repair for Ischemic and Nonischemic Functional Mitral Regurgitation}

Since the first repair of ischemic FMR in 1981, referral for repair of ischemic and nonischemic functional regurgitation has increased to 236 patients with analysis possible in all patients. Compared with patients with rheumatic $(P<$ $.0001)$ and myxomatous disease $(P<.0001$, paired $t$ test $)$, this cohort is significantly more advanced in age (mean, $69 \pm 10$ years; IQR, 63-77). Consistent with current understanding of the cause of FMR, there was a highly statistically significant correlation with the degree of cardiac dysfunction in this group as reflected in ejection fraction (mean, $43 \% \pm$ $13 \%$; IQR, $35 \%-55 \% ; P<.0001$ vs rheumatic and myxomatous by paired $t$ test). All had moderate to severe MR, with severe MR noted in $62 \%$ of preoperative studies. Previous cardiac operation was more predominant in this group, with 43 of 236 patients (18\%) having MV repair done as a reoperation, including 32 previous CABGs, 6 previous CABGs and AVRs, and 3 previous AVRs.

Mean CPB time was $109 \pm 32$ minutes (IQR, 90-120), and mean aortic crossclamp time was $75 \pm 24$ minutes (IQR, 59-90). Repair included ring reduction annuloplasty in all patients. Although the flexible Cosgrove $(n=146)$ and Duran $(\mathrm{n}=26)$ rings were most commonly implanted in patients earlier in the series, we now primarily use rings more uniquely suited for FMR (24 Carpentier-Edwards Physio [Edwards Lifesciences], 7 Geoform [Edwards Lifesciences], and 7 Medtronic Future GC rings). In comparison with the other causes, undersized rings were used with a median implant size of $28 \pm 2.6 \mathrm{~mm}$ (IQR, 28-30), which is significantly smaller than those used in the myxomatous group $(P<.0001)$. In sharp contrast with the other groups, 182 of 236 patients $(77 \%)$ underwent concomitant procedures that included $106 \mathrm{CABGs}$ and 120 other cardiac 
procedures. The 30-day mortality for FMR was significantly higher than in the other groups $(\mathrm{n}=11,4.7 \% ; P<.0001 \mathrm{vs}$ myxomatous and $P=.01$ vs rheumatic, chi-square). The $10-, 20-$, and 30 -year survivals of $44 \%, 4 \%$, and $0 \%$, respectively, were significantly lower than the other cohorts (Figure 2, log-rank $P<.0001$ ), whereas the freedom from MV reoperation was only $63 \%$ at 10 years (Figure 6).

\section{DISCUSSION}

Data from the Framingham study showed that MV prolapse is among the most common cardiovascular abnormalities affecting the general population $(2.5 \%$ of men and $7.6 \%$ of woman) and certainly the most common human heart valve abnormality. ${ }^{10}$ Although progression to severe MR is an uncommon complication overall, the prevalence of prolapse in the community assures its place as the most common cause of MR in North America. Rheumatic MV disease remains a common condition in Third World countries, and data regarding the durability of repair remain important for surgeons worldwide. FMR is increasingly recognized as a harbinger of poor long-term outcomes. ${ }^{11}$

Results of MV surgery up to 29 years postoperatively have been reported. Dr Carpentier's series of rheumatic valve repair demonstrated survival of $89 \% \pm 19 \%$ at 10 years and $82 \% \pm 18 \%$ at 20 years with freedom from reoperation of $55 \% \pm 25 \%$ at 20 years. ${ }^{12}$ Our results are similar given that the Carpentier series was for isolated MR only and excluded patients with associated aortic valve disease and coronary artery disease; these patients were not excluded from our study. This report also shows that at 30 years, only $10 \%$ of patients with rheumatic cause remain free of reoperation. Carpentier reported updated long-term results for degenerative valve disease for a total of 2273 patient years of follow-up giving a 20 -year survival of $48 \%$ and freedom from reoperation between $83 \%$ and $92 \%$, depending on the presence of anterior leaflet involvement. ${ }^{13}$ As in the rheumatic series, these data excluded associated "cardiac

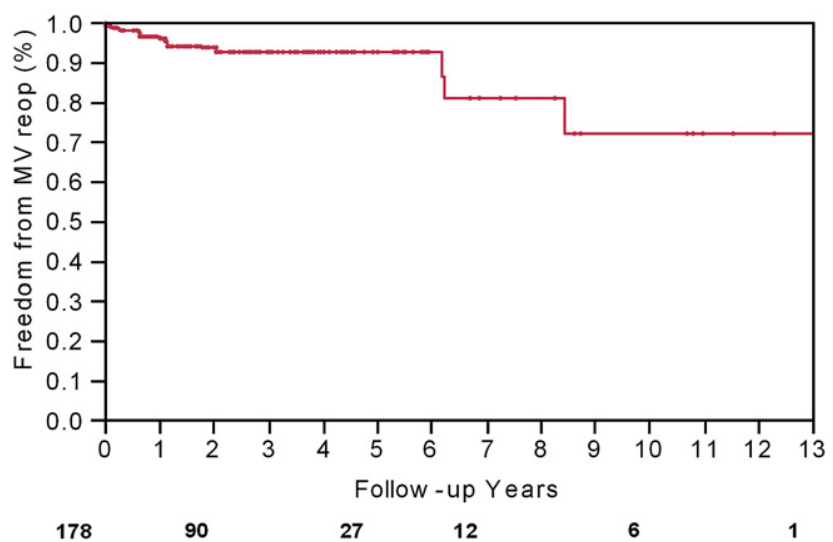

FIGURE 6. Kaplan-Meier actuarial freedom from MR reoperation after repair of FMR up to 12 years postoperatively. $M V$, Mitral valve. or vascular procedures" and ischemic heart disease; we have included both and have found comparable 20-year survival and durability.

Patients with coronary artery disease were included in the long-term Mayo Clinic results for myxomatous disease, ${ }^{14}$ with survival of MV replacement inferior to repair of anterior or posterior leaflet pathology; despite a higher reoperation rate for anterior versus posterior repairs, the overall reoperation rate for MV replacement was not different for either anterior or posterior repair. A later update from the same authors reported a subset analysis in elderly patients and confirmed that restoration of life expectancy is similar in the elderly and the young and that recent survival improvement does benefit elderly patients who should also be considered for repair. ${ }^{15}$ We agree that all patients should be offered repair on the basis of valve morphology, not patient age. ${ }^{16}$

Repair of the myxomatous MV is a durable operation. An annuloplasty ring is essential for repair to remodel the annulus and stabilize the repair for long-term durability. An earlier analysis from Brigham and Women's Hospital confirmed markedly inferior results of freedom from progression of myxomatous disease without ring placement (67\% $\pm 12 \%$ at only 5 years). ${ }^{17}$ This has been confirmed in many large series and remains a universally adapted tenet of MV repair at this time. David and colleagues ${ }^{18}$ discussed that repairs without rings resulted in larger MV area but reiterated Carpentier's philosophy that an MV ring converts an anatomically bicuspid valve to a functional monocuspid valve with little posterior valve leaflet movement. David and colleagues did not find a difference in MV area between the rigid Carpentier ring and the flexible Duran ring, consistent with our previous observations that MVA is larger with no ring but not different between rigid and flexible rings. ${ }^{7}$ It has been demonstrated that the human MV is dynamic throughout the cardiac cycle (decreasing its annular circumference and area in systole) and that this geometry is preserved with the use of a flexible ring. ${ }^{19}$ David and colleagues $^{20}$ and Okada and colleagues ${ }^{21}$ also reported evidence of superior early left ventricular function with flexible rings, demonstrating better diastolic flow through the MV with exercise. This remains highly controversial with animal data from Stanford contradicting both notions (left ventricular performance in dogs and preservation of geometry in sheep). ${ }^{22,23}$

Freedom from reoperation for anterior leaflet repair is inferior to that of a posterior repair. There is little question that $\mathrm{P} 2$ leaflet prolapse treated with posterior resection and annuloplasty is superior to the repairs currently performed on the anterior leaflet. ${ }^{24,25}$ Commonly used anterior repair techniques include chordal shortening, commissuroplasty, artificial polytetrafluoroethylene (Gore-Tex) cord placement, and Alfieri ETE repair. Gillinov and colleagues ${ }^{24}$ reported chordal shortening as a significant predictor of poor MVP 
durability and 10 years later ${ }^{25}$ reported improved results with isolated anterior repair ( $89 \%$ success at 10 years). ${ }^{25}$ Despite a higher freedom from reoperation rate than reported previously, $11 \%$ of patients had return of $3+$ or $4+$ MR within 1 year of repair. Our data confirm these findings, and this remains a continuing challenge. We have used ETE repair for isolated A2 prolapse (including a ring annuloplasty) and noted mid-term results similar to those reported by Alfieri and colleagues. We have reported excellent results when the same technique is used for the prevention of SAM (detected pre-bypass or based on operative findings) but confirm poor results when it is used as a "bailout" procedure for a failed complex MVP. ${ }^{9}$

FMR continues to be an increasingly studied and debated indication for MVP. The somewhat historical nature of this series (with the first ischemic valve repair in 1981) is reflected in that the majority of patients had flexible, $\mathrm{C}$-shaped MV rings implanted, and this may be an important reason for our significantly lower freedom from MV reoperation at 10 years. The introduction of the newer generation of saddle-shaped rigid and semi-rigid remodeling rings ${ }^{26}$ may improve on these results, or perhaps alternate technology, such as described by Kron and colleagues, ${ }^{27}$ will prevent recurrent MR from progressive left ventricular remodeling.

For incision use, we have pursued minimally invasive approaches for MVP since 1996 and have reported comparable results to traditional sternotomy. ${ }^{28,29}$ As we recently reported, ${ }^{29}$ the lower hemisternotomy continues to be our favored approach with no difference in outcomes for equivalent patients undergoing sternotomy. Although the thoracotomy approach is not primarily used, we have reported this to be an excellent alternative in patients with patent grafts from CABG surgery, and it will continue to become an important incision as laparoscopic and robotic repair are further considered for MVP. ${ }^{30}$

\section{CONCLUSIONS}

The long-term results of MVP for 3 causes indicate that repair of myxomatous disease is long-lasting and should stimulate earlier referrals under the new guidelines of the American Heart Association and American College of Cardiology. ${ }^{31}$ Although rheumatic disease is repairable, virtually all patients who survive long enough will require reoperation. Repair results for ischemic and nonischemic FMR have been less than effective but are promising with further maturation of technology.

\section{References}

1. Cohn LH, Collins JJ Jr. Editorial: Surgical treatment of mitral stenosis: a medical milestone. N Engl J Med. 1973;289:1035-7.

2. Harken DE, Ellis LB, Ware PF, Norman LR. The surgical treatment of mitral stenosis. N Engl J Med. 1948;239:801.

3. Lillehei CW, Gott VL, DeWall RA, Varco RL. Surgical correction of pure mitral insufficiency by annuloplasty under direct vision. Lancet. 1957;77:446-9.
4. Lillehei CW, Levy MJ, Bonnabeau RC. Mitral valve replacement with preservation of papillary muscles and chordae tendinae. J Thorac Cardiovasc Surg. 1964; 47:532-43.

5. Carpentier A. Cardiac valve surgery-the "French correction". J Thorac Cardiovasc Surg. 1983;86:323-37.

6. Duran CG, Revuelta JM, Gaite L, et al. Stability of mitral reconstruction surgery at 10-12 years for predominantly rheumatic valvular disease. Circulation. 1988; 78(Suppl):191-6.

7. Cohn LH, DiSesa VJ, Couper GS, et al. Mitral valve repair for myxomatous degeneration and prolapse of the mitral valve. J Thorac Cardiovasc Surg. 1989;98:987-93.

8. Deloche A, Jebara VA, Relland JYM, et al. Valve repair with Carpentier techniques: the second decade. J Thorac Cardiovasc Surg. 1990;99:990-1002.

9. Brinster DR, Unic D, D'Ambra MN, et al. Midterm results of the edge-to-edge technique for complex mitral valve repair. Ann Thorac Surg. 2006;81:1612-7.

10. Savage DD, Garrison RJ, Devereaux RB, et al. Mitral valve prolapse in the general population: 1. Epidemiological features: the Framingham study. Am Heart J. 1983;106:571-6.

11. Romano MA, Bolling SF. Update on mitral repair in dilated cardiomyopathy. J Card Surg. 2004;19:296-400.

12. Chauvaud S, Fuzellier JF, Berrebi A, et al. Long term (29 years) results of reconstructive surgery in rheumatic mitral valve insufficiency. Circulation. 2001;104:I: $12-5$.

13. Braunberger E, Deloche A, Berrebi A, et al. Very long-term results (more than 20 years) of valve repair with Carpentier's techniques in nonrheumatic mitral valve insufficiency. Circulation. 2001;104:I:8-11.

14. Mohty D, Orszulak TA, Schaff HV, et al. Very long-term survival and durability of mitral valve repair for mitral valve prolapse. Circulation. 2001;104:I1-7.

15. Detaint D, Sundt TM, Nkomo VT, et al. Surgical correction of mitral regurgitation in the elderly: outcomes and recent improvements. Circulation. 2006;114:265-72.

16. Gogbashian A, sepic J, Soltesz EG, Nascimben L, Cohn LH. Operative and long term survival of elderly is significantly improved by mitral valve repair. Am Heart J. 2006;151:1325-33.

17. Cohn LH, Couper GS, Aranki SF, et al. Long term results of mitral valve reconstruction for regurgitation of the myxomatous mitral valve. J Thorac Cardiovasc Surg. 1994;107:143-51.

18. David TE, Armstrong S, Sun Z, Daniel L. Late results of mitral valve repair for mitral regurgitation due to degenerative disease. Ann Thorac Surg. 1993;56:7-14.

19. Gillinov AM, Cosgrove DM, Shiota T, et al. Cosgrove-Edwards annuloplasty system: midterm results. Ann Thorac Surg. 2008;69:717-21.

20. David T, Komeda M, Pollick C, Burns RJ. Mitral valve annuloplasty: the effect of the type on left ventricular function. Ann Thorac Surg. 1989;47:524-8.

21. Okada Y, Shomura T, Yamaura Y, Yoshikawa J. Comparison of the Carpentier and Duran prosthetic rings used in mitral reconstruction. Ann Thorac Surg. 1995;59:658-63.

22. Castro LJ, Moon MR, Rayhill SC, et al. Annuloplasty with flexible or rigid ring does not alter left ventricular systolic performance, energetics or ventricular-arterial coupling in conscious, closed-chested dogs. J Thorac Cardiovasc Surg. 1993; 105:643-59.

23. Glasson JR, Green GR, Nistal JF, et al. Mitral annular size and shape in sheep with annuloplasty rings. J Thorac Cardiovasc Surg. 1999;117:302-9.

24. Gillinov AM, Cosgrove DM, Blackstone EH, et al. Durability of mitral valve repair for degenerative disease. J Thorac Cardiovasc Surg. 1998;116:734-43.

25. Gillinov AM, Blackstone EH, Alaulaqi A, et al. Outcomes after repair of the anterior mitral leaflet for degenerative disease. Ann Thorac Surg. 2008;86:708-17.

26. Votta E, Maisano F, Bolling, et al. The Geoform Disease-Specific Annuloplasty system: a finite element study. Ann Thorac Surg. 2007;84:92-102.

27. Kron IR, Green GR, Cope JT. Surgical relocation of the posterior papillary muscle in chronic ischemic mitral regurgitation. Ann Thorac Surg. 2002;74:600-1.

28. Mihaljevic T, Cohn LH, Unic D, et al. One thousand minimally invasive valve operations: early and late results. Ann Surg. 2004;240:529-34.

29. McClure RS, Cohn LW, Wiegerinck E, et al. Early and late outcomes in minimally invasive mitral valve repair: an eleven-year experience in 707 patients. $J$ Thorac Cardiovasc Surg. 1998;116:734-43.

30. Byrne JG, Aranki SF, Adams DH, et al. Mitral valve surgery after previous CABG with functioning IMA grafts. Ann Thorac Surg. 1999;68:2243-7.

31. American College of Cardiology, et al. ACC/AHA 2006 guidelines for the management of patients with valvular heart disease: a report of the American College of Cardiology/American Heart Association Task Force on Practice Guidelines (writing committee to revise the 1998 Guidelines for the management of patients with valvular heart disease). J Am Coll Cardiol. 2007;48:e1-148. 


\section{Discussion}

Dr D. Adams (New York, NY). I would like to disclose that I am a coinventor of the Physio II (Edwards Lifesciences, Irvine, Calif) and ischemic mitral regurgitation annuloplasty rings and have consulting and royalty agreements with Edwards. Dr DiBardino, I enjoyed your presentation and congratulate you on this effort to provide us with the long-term follow-up of Dr Cohn's impressive series of valve reconstruction in more than 1500 patients performed over a 36-year period. The fact that the overall mortality in this series averaged $1.3 \%$ with no significant difference in risk regardless of decade of surgery is a testament to Dr Cohn's skill and leadership of one of the most outstanding programs in our specialty. My first question relates to the completeness of your echo and reoperation followup. Death is a relatively easy variable to confirm in a retrospective analysis. Reoperations and particularly recurrence of mitral regurgitation rates are more challenging. Please give us a sense of how confident you are in the latter 2 event rates you present?

Dr DiBardino. Thank you, Dr Adams, for your question, and it is nice to be graduating from a program and to see so many people who have come before me do such great things in the field. In regard to the completeness of the data, the survival data are $98 \%$ complete largely because of the use of the death index, as you acknowledge, and that is certainly the easiest hard end point to achieve. The reoperation data are $83 \%$ complete; data for the myxomatous group are approximately $90 \%$ complete. The data are not perfect, and we ran into several problems. One is, of course, patients with international and even national referrals are tough to investigate. The other problem is when you try to look at it over 36 years, patients who died, say, at 20 years postoperatively 10 years ago, it might be possible to identify whether they had a reoperation before death, and I only included patients I was $100 \%$ sure of a hard and fixed end point. So the $83 \%$ we had is the best we could do. I think it fairly represents the patients who were at risk. Now, the echocardiogram data are, by far, the toughest of the 3 to get, for many of the same reasons. The mean of the echo data I presented here is only 4 years. The patients who are in good functional status, it seems, don't like to get echocardiograms much past that, and that was a problem I ran into trying to contact these patients and get these echo follow-ups. So that is the toughest one to get, and it is about two thirds. We hoped to do a lot better.

Dr Adams. In your degenerative group, your most common strategy for bileaflet prolapse is a posterior leaflet repair and ring annuloplasty. A true anterior leaflet prolapse is actually not corrected by posterior leaflet or annular surgery. Please clarify exactly what you mean in your article by anterior leaflet involvement in these patients. Was this assessed by preoperative echocardiography or intraoperative valve analysis?

Dr DiBardino. That is an excellent point. The 2 superimposed curves I showed, one is for posterior only and the other is for anterior. This is by intraoperative note review. So these would be mostly by the saline test. Yes, they reflect sort of the gestalt of the echo in the surgeon's mind going into the operating room and especially the intraoperative transesophageal echocardiogram before repair, but they really were as described, by saline test, and your point is very well taken. What this really reflects is not an echo finding of true bileaflet prolapse but a tendency toward prolapse, chordal elongation, and so forth, just as you say. And going back so many years over so many patients, because that was the most consistent way I had of identifying what the valve "looked like," it is what I went with, and that reflects, as you say, the types of repairs the patients underwent. So that is absolutely right. This is an intraoperative inspection.

Dr Adams. I think that will be important to clarify in your article.

My next question is about rheumatic repair and degenerative repair. The survival was similar but the reoperation rate was higher in the rheumatic group. How do you reconcile that?

Dr DiBardino. The patients who were followed for rheumatic disease were followed for a lot longer. The first operation for ischemic disease was in 1981, and the first operation for rheumatic disease was in 1972. So the follow-up is longer. Also, the reoperation data on the patients with FMR are somewhat tainted by the fact that many of them did not survive the first 10 years. So they fall out of play in the Kaplan-Meier analysis.

Dr Adams. Your 10-year freedom of reoperation was only $84 \%$ in the anterior leaflet repair subgroup. In your article, you infrequently use polytetrafluoroethylene neochordae or chordal transfer or leaflet transfer, which are commonplace in most centers today. Can you clarify your current strategy to repair anterior leaflet prolapse, and do you have echo data regarding recurrence of mitral regurgitation in this retrospective subgroup?

Dr DiBardino. That is a very keen observation. You are right. In fact, chordal transfer has never been something that Dr Cohn has used. I can't think of a single case identified in this series. He just never liked it. The anterior polytetrafluoroethylene (GoreTex; WL Gore \& Associates Inc, Newark, Del) chordal resuspension has been used, as you say, infrequently compared with most centers. It is not something that we prefer if we can get away without doing it. Commissuroplasty is used commonly in those patients whom we identified as having anterior prolapse toward 1 commissure, and we reported in 2006 about our use of the Alfieri stitch, mostly prophylactically when high-risk SAM is identified, but that also fixes that kind of a problem.

In terms of isolated echo data, I do not have isolated echo data broken down by cause.

Dr Adams. Can you clarify your current approach to patients with ischemic mitral regurgitation given your high reoperation rates during long-term follow-up? Have you changed your ring or repair strategy currently or are you doing more replacements in this subgroup?

Dr DiBardino. The answer to your question is that the ring designs influenced what we saw over the years. When you look at this reoperation rate, you are looking into the past in terms that are looking at patients who received mostly C-band Cosgrove rings. Dr Bolling is probably about to vomit here listening to this, but it is true. And I think that the ring designs change, and certainly we are applying more of the GeoForm and Physio rings (Edwards Lifesciences), and hopefully you will show us some data on the Physio II that is more promising.

Dr S. Bolling (Ann Arbor, Mich). Dan, I rise to congratulate you, your institution, and Dr Cohn on a fantastic series. I have one specific question. Your mortality by decade was no different, which is a testament to the excellent care for these patients at your institution. I know your follow-up for reoperation rate is only $83 \%$ complete by echo, but were you able to identify factors that influenced your reoperation rate? Obviously our surgical techniques over the 
time of this wonderful long series have changed. Were you able to identify something, the absence of a ring or no ring or some other factor, that led us to improve our reoperation rates?

Dr DiBardino. We at the Brigham and many others have shown that the absence of a ring was an independent predictor of reopera- tion for MV disease. That remains true, and I am in the process of trying to perform a more formal analysis. I am trying to develop a scoring system looking at predictors of reoperation. It is still not ready for prime time yet. I hope to be able to speak about it sometime in the future. 